A NOTE ON BERGAMOT OIL.

\title{
CXXXV.-A Note on Bergamot Oil and other Oils of the Citrus Series.
}

By Herbert Edward Burgess and Theodore Henry Page.

\section{Bergamot Oil.}

Is continuation of our researches on oils of the Citrus series, we have recently examined bergamot oil, of which, up to the present time, the constituents are stated to be limonene, linalool, linalyl acetate, and limettin. To these we have been able to add acetic acid, octylene, pinene, camphene, and limene. Every care was taken to ensure that the purity of the oil used for this investigation was beyond suspicion. It had the following constants : sp. gr. 0.885 at $15^{\circ} / 15^{\circ} ;[a]_{\mathrm{D}}+8^{\circ} ; n_{\mathrm{D}}$ 1.4648 at $20^{\circ}$, these values being in accordance with the recognised figures for a pure specimen of the oil.

Acetic Acid.-The first fractions of bergamot oil have always a somewhat pungent odour, and on fractionation this becomes very marked in the lowest fraction. Evidently this characteristic is due to a volatile acid, for litmus paper held in the upper part of the vessel containing the fraction was markedly affected. Moreover, this fraction reacted vigorously with moist barium carbonate, and the neutral solution gave with ferric chloride a colour reaction like that of acetic acid. On analysis, the barium salt, gave the following result, which agrees closely with the number calculated for barium acetate.

0.469 barium salt gave $0.427 \mathrm{BaSO}_{4} . \quad \mathrm{Ba}=53.5$.

$$
\mathrm{Ba}\left(\mathrm{CH}_{3} \cdot \mathrm{CO}_{2}\right)_{2} \text { requires } \mathrm{Ba}=53 \cdot 7 \text { per cent. }
$$

The free acid may be due to slight hydrolysis of the linalyl acetate, of which a large proportion is present in this oil, but, on the other hand, we obtained a sufficient amount from lemon oil to give qualitative tests, although this oil only contains small quantities of esters. We believe that free acetic acid is usually present in the Citrus oils, 
for the first fractions are always somewhat pungent, although not so markedly as in the case of bergamot oil.

Octylene.-By careful fractionation with a 5-section modified Young's evaporator still-head, we obtained a fraction boiling between $150^{\circ}$ and $155^{\circ} / 764 \mathrm{~mm}$., and having the following constants : sp. gr. 0.851 at $15^{\circ} / 15^{\circ},[a]_{\mathrm{D}}-3.5^{\circ}, n_{\mathrm{D}} 1.4593$ at $16.5^{\circ}$.

Owing to the very small quantity, no further separation could be effected, but the constants certainly show the presence of a light substance mixed with much pinene (the next fraction). This product also had the odour of octylene, which we had previously found in lemon oil (vide infra).

As there was some doubt as to whether the substance found in lemon oil had not been reduced to the corresponding paraffin by distillation over sodium, this fraction was not treated with this metal, but oxidised at once with potassium permanganate solution. The light substance was completely oxidised to butyric acid, and the very small quantity of oil escaping oxidation had none of its characters, but resembled pinene; its refractive index at $16^{\circ}$ being 1.4661 . From these facts, we feel justified in calling this substance an octylene and not an octane, and we believe it to be the lowest member of the olefinic series hitherto found in essential oils.

Pinene.-The fraction boiling at $157-158^{\circ} / 764 \mathrm{~mm}$. had sp. gr. 0.859 at $15^{\circ} / 15^{\circ},[a]_{\mathrm{D}}-8.3^{\circ}, n_{\mathrm{D}} 1.4660$ at $16.5^{\circ}$.

By treatment with dry hydrogen chloride, the characteristic hydrochloride (m. p. $125^{\circ}$ ) was obtained.

Camphene.-The fraction boiling at $164-165^{\circ} / 764 \mathrm{~mm}$. had sp. gr. 0.868 at $15^{\circ} / 15^{\circ},[a]_{\mathrm{D}}-22.8^{\circ}, n_{\mathrm{D}} 1.4766$ at $16.5^{\circ}$.

By treatment with glacial acetic acid and a small quantity of sulphuric acid in the usual way, we obtained from this fraction isoborneol (m. p. $203^{\circ}$ ), but the quantity was too small to allow of further purification, and it is only by crystallising large quantities that the correct melting point, $212^{\circ}$, can be reached.

Limonene.-This terpene, one of the well-known constituents of bergamot oil, we obtained with a rotation of $+88^{\circ} 30^{\prime}$ in a $100 \mathrm{~mm}$. tube.

Limene.-After the removal of the linalyl acetate, we obtained a small fraction which gave the characteristic hydrochloride (m. p. $79^{\circ}$ ) on treatment with dry hydrogen chloride in dry ether (this vol., p. 414).

\section{Lemon Oil.}

Octylene.-In examining the most volatile terpenes from very large quantities of lemon oil, we obtained by repeated fractionation a substance having the following properties: b. p. $123-124^{\circ} / 768 \mathrm{~mm}$; 
sp. gr. $0.7275 ;[a]_{\mathrm{D}} \pm 0 ; n_{\mathrm{D}} 1.4066$ at $15^{\circ}$; mol. refraction, 38.54 ; the value calculated for $\mathrm{C}_{8} \mathrm{H}_{18}$ being $38 \cdot 87$, and for $\mathrm{C}_{8} \mathrm{H}_{16}, 38 \cdot 28$.

0.2580 gave $0.7936 \mathrm{CO}_{2}$ and $0.3594 \mathrm{H}_{2} \mathrm{O} . \quad \mathrm{C}=83.89 ; \mathrm{H}=15.48$. $\mathrm{C}_{8} \mathrm{H}_{13}$ requires $\mathrm{C}=84.21 ; \mathrm{H}=15 \cdot 79$ per cent.

Vapour density determinations by Victor Meyer's method gave the numbers 112 and 117 for the molecular weight. A bromination showed that only about one-fifth of a mol. of bromine was taken up by $1 \mathrm{~mol}$. of the substance : $0.406 \mathrm{gram}$ of the compound absorbed 0.12 gram of bromine. All these facts seem to point to the substance being one of the octanes. On the other hand, another portion treated with potassium permanganate gave butyric acid, recognised by its odour and by the analysis of the silver salt.

$0 \cdot 1025$ gave $0.0565 \mathrm{Ag} . \quad \mathrm{Ag}=55 \cdot 12$.

$\mathrm{C}_{3} \mathrm{H}_{7} \cdot \mathrm{CO}_{2} \mathrm{Ag}$ contains $\mathrm{Ag}=\mathbf{5 5} \cdot 38$ per cent.

This contradictory result is explained by the fact that the latter portion had not been distilled over sodium. The other portion had been thus treated to remove oxygenated impurities before its nature was suspected, and had become reduced from an octylene to an octane. This explanation is supported by the behaviour of the corresponding fraction of bergamot oil, as already mentioned.

We have evidence which makes it probable that octylene is a normal constituent of the Citrus oils.

\section{Distilled Oil of Limes.}

In continuation of our work on this oil (this vol., p. 414), we have been able to separate the phenylurethane of a second substance having a somewhat lower boiling point than ordinary terpineol from that fraction, which has the distinctive odour of this oil in a marked degree. The phenylurethane is more soluble than that of ordinary terpineol, and was found in the residue left after distilling off in steam the excess of terpineol from the filtrate obtained in the preparation of the urethane. It crystallised in tufts of needles, melted at $132^{\circ}$, and gave on hydrolysis a small quantity of oil having the peculiar odour of distilled oil of limes. 